\title{
The same old story: the reproduction and recycling of a dominant narrative in research on physical education for girls
}

\author{
David Kirk and Kimberly L Oliver
}

\begin{abstract}
Our purpose in this paper is to show how a particular narrative, what we call here 'the same old story', about girls and physical education is maintained and reproduced by many of the researchers who study this topic, and by sections of the media who report on some of this research. We believe we need to understand the extent of the contribution researchers of girls and physical education make to the same old story if we are to contribute to a process of bringing about change for the better for all girls. First of all, we summarise the collective knowledge from social, pedagogical and historical research on girls and physical education overviewed by Flintoff and Scraton in 2006, before going on to examine some of the research literature post-2006 that we think reproduces the same old story in a variety of ways. Next we present a case study of the treatment of the report of a large-scale study in England by the media to show not only that newspapers and other media outlets are parasitic upon research but that they also invariably simplify, sensationalise and misrepresent the findings of studies of girls and physical education. We conclude that this topic of study, like the broader field of physical education and sport pedagogy, is marred by poor citation practices and a consequent general lack of systematic building on previously published studies. Moreover, we suggest that there appear to be few programmes of research and a marked absence of a broader programme of interlocking research studies that could produce genuine developments in practice. Finally, we propose that a large part of a shared mission for this field of inquiry is that it must become more focused on how we go about improving the situation for girls in physical education, building on what we already know from activist studies and other student-centred interventions.
\end{abstract}

Keywords: girls and gender, physical education, pedagogy, activist research

\section{Introduction}

Writing in the early 1990s, Patricia Vertinsky (1992) pinpoints the moment when things went horribly wrong for girls and physical education, the implementation in various countries of equal opportunities legislation in the 1970s and early 1980s. This is not to say, as Vertinsky is 
keen to show, that all was well before this legislation. But its introduction created the issue that is the central topic of this paper, the genesis of a narrative about 'the problem' of girls in physical education. The wider impact of this legislation, where it helped create more equitable and just social institutions and practices, was without question right and necessary. But where it touched on physical education, particularly in North America, the assumption was made that coeducational programmes would be more equitable than gender segregated programmes, an assumption that Vertinsky (p.378) notes was not warranted since "equal access did not ensure equal participation". Instead, what the antisexist legislation did was to put boys and girls together in physical education classes that were run according to boys' rules and standards, inevitably providing proof to sexist opponents of equal opportunities legislation that girls and women were in fact 'the weaker sex'. Even where legislation was framed in ways that supported coeducational physical education but provided enough exemptions to permit single sex programmes to continue, as it was in the UK's Sex Discrimination Act of 1975, this watershed moment brought physical education for boys and girls into direct comparison, and so the seeds of the same old story were sown.

Vertinsky (1992, pp. 378-9) maps out the basic elements of the narrative of the same old story persuasively and in some detail. What it came down to, she notes, was that, "if girls did not avail themselves of opportunities for play they were blamed for having the 'wrong' attitude". It was girls' fault that they did not like vigorous physical activity, that they did not want to compete to win, that they avoided physical contact, that they valued being with friends over being on the winning team, and that they dropped out of physical education in increasing numbers throughout their high school years. As Vertinsky notes, much hope was placed in teachers to carry through this reform. But teachers who had taught and had been trained in single-sex environments, even those who were committed to co-educational physical education, struggled in practice to treat all students the same, as the equal opportunities rhetoric seemed to imply.

Much of the research Vertinsky cites in this 1992 paper already recognised the simplicity of the practices that seemed to flow from this well-intentioned legislation. On the basis of this work she was able to write that

"Efforts to promote participation tend to severely underestimate the ways that girls' perceived opportunities are already bounded by previous socialization into play and 
sport from early childhood, the level of support from parents, peers, and teachers (especially in the primary years), and economic opportunity, class, and race." (Vertinsky, 1992, p.385)

Despite the efforts of generations of feminist researchers who have tried to shift the terms of the narrative from blaming girls to recognition of a complex interaction of factors centred on the patriarchal order, the same old narrative has resisted and persisted. As a case in point, the Women's Sport and Fitness Foundation (2010) in the UK produced a 'fact sheet' that shows how firmly entrenched is the basic outline of the same old narrative. The 'fact sheet' summarises headline results from a range of surveys of young people in the UK conducted between 2007 and 2010. The reporting follows more or less the same theme of showing that girls are less active than boys, more girls than boys decline in activity more dramatically during adolescence, girls believe boys' activities to be more important, and that girls see exercise as a way of becoming and being thin.

Our purpose in this paper is to show how the same old story about girls and physical education is maintained and reproduced by many of the researchers who study this topic, and by sections of the media who report on some of this research. We are concerned about the perpetuation of the same old story in the work of researchers and the reporters of this research in the popular press and other media outlets because we think it is this group who should be leading the challenge to change this narrative. We believe we need to understand the extent of the contribution researchers of girls and physical education make to the same old story if we are to contribute to a process of bringing about change for the better for all girls.

We begin by summarising the collective knowledge from social, pedagogical and historical research on girls and physical education overviewed by Flintoff and Scraton in 2006, before going on to examine some of the research literature post-2006 that we think reproduces the same old story in a variety of ways, typically by being unaware of or perhaps deliberately omitting what is clearly shown by the Flintoff and Scraton chapter and other sources to be already known about this topic. Next we present a case study of the treatment of the report of a large-scale study in England by the media to show not only that newspapers and other media outlets are parasitic upon research but that they also invariably simplify, sensationalise and misrepresent the findings of studies of girls and physical education. In our conclusion we 
attempt to understand some of the trends in this research, some of the reasons why it perpetuates the same old story, and what might be done to address this problem.

\section{The same old story: the evidence}

While most peer reviewed publications on girls and physical education provide short reviews of previously published research, Flintoff's and Scraton's (2006) chapter in the Handbook of Physical Education is one of the few detailed reviews of research on this topic. That said, the review is selective and has a particular focus, on curriculum, teachers, teaching and teacher education, and girls' perceptions and experience, these being the three main dimensions of pedagogy. And reflecting the location of its authors, both geographically and paradigmatically, the chapter places its main emphases on English-language publications in Europe and the UK and includes studies that are mainly informed by some version of feminist theory. It is, nevertheless, the only recent comprehensive published review of what we have learned from research about girls and physical education and as such provides us with a valuable resource to interrogate our argument about the same old story.

Before they begin to review the pedagogical research on girls and physical education, Flintoff and Scraton remind us that there is a considerable historical literature on this topic and indeed that women played a significant leadership role in the development of physical education in the UK and elsewhere since at least the end of the nineteenth century. The 'female tradition', as Fletcher (1984) dubbed it, was always controversial since girls' and women's participation in organised forms of physical activity such as gymnastics and some sports challenged deepseated social mores about masculinity and femininity. This overview of historical studies also reminds us that the issues surrounding girls and physical education have a long history in education systems amounting to over a century and a half in some countries. This point is important for our argument about the same old story because it has over time become deeply ingrained in the collective consciousness of populations, including the institutions that prepare teachers of physical education and that develop sports. There can be no question that, while some things may have changed over this century or more in terms of girls and physical education, there have also been important continuities between past and present that are wellestablished and thus very powerful.

Flintoff and Scraton note a general trend in the research on girls and physical education reflected in the pedagogy literature more broadly, which is a shift of the attention of 
researchers from concerns about teachers, teaching and teacher education, to curriculum and more recently to learners and learning (Kirk, 2010). This is another significant outcome of their review, since the papers they cite in relation to girls' perceptions and experiences of physical education date with only one or two exceptions from 2000. In other words, we know more about teachers and the curriculum in relation to this topic than we do about girls themselves. While we think there is some published work from the early to mid-1990s that Flintoff and Scraton did not include, nevertheless we might pause to wonder why it has taken researchers so long to consider it important to listen to the voices of girls.

Their review of studies of teachers, teaching and teacher education and of curriculum provides some important insights. One of the most significant is that gender inequalities and stereotyping are part of teachers' own experiences both of their school physical education and sport participation and their education as physical education student teachers. These are, moreover, powerful normalising processes that individuals can challenge only at personal risk and cost. Teachers are then among the primary agents for reproducing existing gender relations in physical education, not as individual choices they make but as part of wider, sedimented and powerful institutional processes. Unsurprisingly, then, Flintoff and Scraton note research which suggests male and female teachers practice slightly different teaching styles, with women engaging with girls in more interpersonal ways, in contrast to male teachers' more direct instructional styles. Their review shows the vitally important role teachers play as models of gendered behaviour for both girls and boys, and how hard it is to change these behaviours, even when teachers themselves recognise that there is an issue and willingly engage in change processes.

The curriculum represents a further topic of study for researchers of girls and physical education. Fintoff and Scraton note that this research is strongly influenced by the historical legacy of separate sex classes and high levels of differentiation of activities deemed to be suitable for girls and for boys, leading to strongly entrenched practices of 'genderappropriate' physical activities in the curriculum. They show that differentiation of activities has continued even when initiatives such as the National Curriculum Physical Education in England presented opportunities to offer alternatives. At the same time, and drawing on US research dating from the mid-1980s around the 1972 Title IX development, they show that legislation requiring girls and boys to be taught the same activities together in co-educational classes is not necessarily a step forward in equal opportunities for girls. They cite research 
that shows boys dominate co-ed classes, and that perspectives on the gender-appropriateness of activities remain in place.

Returning to the focus on girls, Flintoff and Scraton show that the research reports considerable variability of experiences and perceptions, suggesting there is no homogenous 'girl' who shares the same experiences and perceptions as her peers. Some girls say they like physical education and some say they do not. Some girls like some activities and others different activities. Citing their own research reported in 2001, Flintoff and Scraton claimed that girls' participation in sport is problematically low, though again there was much variability in terms of intensity and extent of participation. Other research they cite showed that, for girls who do wish to participate in sport, compromises are often required in terms of the construction of their feminine and sexual identities. Despite the variability these studies of girls' experiences and perceptions reveal, Flintoff and Scraton claim they also show that girls are constructed by others, including their teachers and their peers, as inferior to males in physical education and sport contexts. They also claim, citing work published in 2002 and 2003, that research had only just begun to consider the experiences and perceptions of girls from different ethnic, religious and social class backgrounds and how their opportunities to be physically active may be shaped by school, family and community. They cite the need for research on 'difference and diversity' as a future focus of studies of girls, gender and physical education.

We suggest that, whatever other merits it possesses, this analysis of the research literature by Flintoff and Scraton provides us with a very helpful means of interrogating the accuracy of our argument about the same old narrative. It provides us with one place to visit to determine whether and to what extent a researcher's claims to originality for their research focus on girls and physical education is credible. This is particularly the case for research carried out after the publication of this chapter in 2006. But it is also the case for some research conducted before this in so far as Flintoff and Scraton provide us with a sense of the critical mass of studies that have investigated particular aspects of pedagogy. Of special interest to us is the absence in their review of studies of interventions in schools that took all three aspects of pedagogy (learning, teaching and curriculum) together, as the organising centre for physical education. 
A review of studies of girls and physical education since Flintoff and Scraton wrote their 2006 piece (sometime in 2004 or 2005) shows two distinct trends. The first is that researchers have indeed begun to answer the call to investigate issues of intersectionality, difference and diversity. The second is that some of the more recent research is located within the discourse of physical activity and public health, much of it utilising public health research protocols centred on interventions.

A need to understand the topic of girls and physical education intersectionally, as we noted earlier, was identified by Vertinsky in her 1992 paper. Some researchers responded to this call. Oliver and Lalik $(2000 ; 2001 ; 2004)$ found that the intersections of race and gender were critical to how girls were learning to think about their bodies and recommended that teachers and researchers try to understand how this intersection influences girls' health-related choices. Benn and her colleagues (see eg. Benn et al, 2011) have developed a line of research that has explored the experiences of Muslim girls in physical education in the UK and Greece. A paper by Azzarito and Solmon (2006) repeated the call for the exploration of intersectionality and difference, as did Flintoff and Scraton in their 2006 chapter. Azzarito and Solmon (2006) reported that young people's meanings about the gendered body intersected with the racial body and functioned to circumscribe girls' orientations toward and access to physical activities. They claimed that constructing more equitable physical education contexts and non-tolerance of sexism and racism should feature prominently in any physical education intervention.

Unfortunately, none of this work in physical education is cited or acknowledged in more recent studies of girls and intersectionality from a public health perspective. For instance, Grieser et al. (2006), as part of the Trial for Activity in Adolescent Girls (TAAG) programme, described an 'exploratory study' that compared African American, Hispanic and Caucasian girls. What they found in terms of the girls' attitudes, preferences and practices in relation to physical activity was already in the literature. They concluded that other factors besides ethnicity impact on attitudes to, and preferences and practices for, physical activity. They also noted that girls may benefit best from interventions designed specifically for them, another point that was already well-established in the literature on girls and physical education. In a related publication reporting findings from the TAGG programme, BarrAnderson et al. (2008) noted that TAAG resulted in only modest improvements in girls' PA 
after 3 years and the improvement was only observed among girls who had been exposed to the intervention during their entire middle school experience.

In another study, Taylor et al. (2008) undertook an investigation of African-American and Latino middle school girls on the premise that "more data are needed to better understand factors related to physical activity participation in adolescent girls" (p. 67). They concluded that "fun, social support, and concern with body image facilitated participation in activity. In contrast, negative experiences in physical education classes, concerns about appearance after activity, and lack of opportunity impeded participation in activity" (p. 67). They cite none of the literature reviewed by Flintoff and Scraton that had already established these factors, and report these findings as if they are new and original insights.

One of the earliest studies of physical education and physical activity levels from a public health perspective accidently (as it were) stumbled across gender differences. McKenzie et al. (2004) reported the findings of the two yearlong Middle School Physical Education Intervention (M-SPAN) project which was among the first to promote the notion of Moderate to Vigorous Physical Activity (MVPA) as the 'gold standard' outcome, noting “A disappointing finding was that the physical activity increase for girls was not statistically significant $(P$ ! 0.08). This occurred despite the vast majority of PE classes being coeducational, permitting boys and girls to be exposed to the same teaching methods in the same classes" (p.1386). Since girls were not the focus of the study then it is perhaps not surprising that there is no research literature included on girls and physical education. This absence did not prevent McKenzie et al proposing that "this result suggests additional intervention strategies may be needed for girls, such as including activities more preferred by girls, single-sex activities, and different motivational and instructional techniques" (p.1386). This was a 'discovery' for McKenzie et al. but it is nonetheless a point already clearly established in the literature.

Further studies have adopted the public health perspective following this lead by McKenzie et al. and the TAGG researchers. An Australian study by Casey et al. (2013) of the Triple G (Girls Get Going) program argued for the importance of recognising that interventions developed in the USA for example may not work in other places such as Australia and thus indigenous Australian programmes are required. A study by Felton et al. (2005) report on the Lifestyle Education for Activity (LEAP) program in which girls were the central focus along 
with a concern for race and location (urban, suburban, rural). This paper reports a case study of one school's success in promoting physical activity in girls. Some researchers have continued post 2006 and the publication of the Flintoff and Scraton overview to study a range of topics relating to girls and physical education, invariably framed by concerns over low levels of physical activity and rising obesity, sometimes intersectional and sometimes not, that we would argue contribute little in the way of new insights or knowledge, including factors influencing girls participation in senior high school physical education courses (Gibbons, 2009), female students' perceptions of gender-role stereotypes (Constantinou et al., 2009), and the effects of choice on the motivation of adolescent girls (Ward et al., 2008) to name a few.

These studies and others share in common either the statement of the obvious (eg. 'girls are more motivated when they have choices') or repeat information we already have. Shen et al.'s (2012) ambitious study of urban African-American girls' participation and future intentions towards physical education, which attempts to provide a gendered basis for the theory of planned behaviour by matching it to a feminist post-structuralist perspective, unaccountably fails to cite relevant and appropriate literature that is well known to its authors. Even well-conducted, relatively theoretically sophisticated research such as Hills (2007) ethnographic study of 12 and 13 year old British girls from a range of ethnicities and mostly lower socioeconomic communities repeats, albeit in a highly articulate fashion, insights that have been in the literature represented by the Fintoff and Scraton review for some time. For instance, after a year in the field Hills concluded:

“The complexity of girls' experiences reinforces the need for the implementation of inclusive teaching practices that can differentiate between the skills and experiences of different girls. The recognition of difference provides a central component of entitlement. These differences, however, are not limited to demarcated social categories such as ethnicity, gender, and disability. This study suggests that inclusive practices are required in girl-only as well as co-educational contexts and across social categories. Within this study, a range of practices that excluded some girls from developing skills were identified and included teasing, marginalisation within games, and the public scaling of bodies. Differentiated practices may necessitate deemphasising competitive outcomes, introducing individualised as well as group 
approaches to learning, integrating multi-dimensional learning environments, and modifying or adapting physical activities.” (Hills, 2007, p.333)

At least in this conclusion Hills brings together all three aspects of pedagogy - teachers, learners, and curriculum - to show that no one aspect provides an answer to the 'problem of girls', and that even when we understand the complexity of the issues we are not at the same time handed ready-made solutions. Unfortunately, when researchers such as Hills reveal this complexity, the response from other stakeholders, such as politicians, policy-makers and funding organisations, is to look for ready-made solutions. A key agency in this process of simplification and thus a key contributor to the perpetuation of the same old story is the media.

\section{Researchers and a parasitic media: a case in point}

The reproductive cycle of the same old narrative is maintained; we suggest, by research that appears to be neither regularly nor systematically informed by the collective body of previously produced and published knowledge about girls, gender and physical education. The research community does not accomplish this feat alone however. It is considerably aided in maintaining the same old narrative by a parasitic media. To illustrate how the media comes in to play on the question of girls and physical education we will use a brief case study to make our point. The report we use to illustrate claim is Changing the Game for Girls, published by the UK-based Women's Sport and Fitness Foundation (WSFF) in May 2012. The study was carried out in partnership with the high-profile UK-based organisations the Youth Sport Trust and the Institute for Youth Sport (IYS) at Loughborough University. The following statement by the lead organisation's Chief Executive provides an insight into how the WSFF position the report:

This report presents new research that offers us the opportunity to begin to understand the causes of low levels of physical activity among girls. The project (the largest of its kind ever carried out in the UK) explores the views of girls - and boys - about physical activity, sport and PE, and the influence of schools, friends and families. It also includes interviews with parents and PE teachers. Importantly, the research points clearly to what can be done to help more girls get and stay active. (Sue Tiball, CE, WSFF, 2012, p.1) 
The claim is made that this is new research, and as such offers a beginning in the process of understanding girls' situations with respect to physical activity. It further claims it is distinctive due to its size and because it offers girls and boys an opportunity to be heard. Moreover as Tiball writes, 'importantly', the study provides insights into how to overcome the problems it identifies. None of the claims made in the statement quoted are strictly accurate, and in some cases they seriously misrepresent much of the previous research that has been conducted.

As we noted, Flintoff and Scraton's (2006) overview shows factors affecting girls' situations with respect to physical education and physical activity have been in the public domain increasingly since at least the middle to late 1980s. Moreover, as their review shows, there have been at least as large scale studies conducted previously, and a number these studies that pre-date the 2012 WSFF report have also given girls and boys opportunities to be heard. Neither is its claim to focus on how to overcome the problem of girls' physical education original, notwithstanding the production of a 'toolkit' for teachers, when set beside a whole line of other interventions including activist research with girls. Finally, what the study claims to have discovered with respect to girls' and boys', parents' and teachers' views about physical activity, sport and physical education, including the influence of schools, friends and family, is not news. These insights, as we noted, have been in the research literature for at least two decades or more.

Perhaps, and arguably, the single most notable feature of this study is that it states in more explicit terms than is often the case that school physical education as a curriculum topic and teachers as agents are very much to blame for many girls' unwillingness to participate. And indeed it is this point that was picked up in numerous media stories reporting the research on the day of the Report's release. Jane Hughes (2012) for the British Broadcasting Corporation (BBC) web site headlined her article with the statement that 'Schools urged to make PE more attractive to girls', while Emma Birchley (2012) for Sky News rather more dramatically wrote that 'PE puts half of girls off exercise for life'. Katherine Faulkner (2010) for the Daily Mail was somewhat more loquacious with her headline of 'Grubby changing rooms and embarrassment at getting sweaty in front of boys mean PE lessons are putting girls off exercise for life'. The Independent journalist Richard Garner (2012), meanwhile, focused on a different finding, that 'Unfeminine' school sports leave girls on the sidelines', while his 
colleague Harriet Walker (2012), with her commentary on these news stories, blamed 'the psychotic gym teachers'.

While this 'insight' may have been news to some of these journalists, calls for radical reform of physical education for girls have been appearing in the research literature for decades. Since this report makes no claims to be an 'academic publication', the lack of references is perhaps, arguably, understandable. But Tiball's introduction, which completely omits to mention any other research on physical education and girls, rather than confirm the originality of this 'new' research, merely feeds the reproductive cycle that lies at the root of the problem of bringing about genuine change that will benefit all girls to lead physically active lives.

Ironically, and to emphasise our point, the IYS conducted another study, covered in January 2005 by Denis Campbell of The Observer newspaper under the header 'Ugly games kit turns girls off PE'. Campbell writes of this earlier study:

The findings of the survey, by the Institute of Youth Sport at Loughborough University, will be unveiled this week to the 250 delegates attending Let's Go Girls, the first conference in Britain on how to tackle young females' dislike of school games. The academics conducted research at 111 schools and among almost 11,000 girl pupils aged 11-16. They found that 30 per cent of the girls surveyed did not like their PE kit, and 40 per cent were self-conscious about their bodies. One in five said they only took part in PE because they had to, 15 per cent did not enjoy it and 3 per cent rarely took part. One in five believed that being good at sport was not important for girls and that it was not 'cool' to display sporting prowess. Worryingly, the researchers found that 30 per cent of girls did not think they would be physically active once they left school. They also discovered that girls become progressively more negative towards sport after the onset of puberty. (Campbell, 2005)

This passage could easily have come from the 2012 report or its associated media stories. Certainly it is difficult to see from this media report what progress has been made between the 2005 and the 2012 initiatives involving at least some of the same organisations. While we might as researchers cry foul and claim our work has been misrepresented, we think we have seen enough of this kind of media reporting of research-led initiatives surrounding girls and 
physical education for us as a research community to develop strategies to counteract the parasitic media, to undermine its simplifications and misrepresentations while at the same time getting accurate messages across to the general public as well as key stakeholders.

\section{Conclusion}

We cited at some length Patricia Vertinsky's 1992 paper to introduce the same old story about girls and physical education. We think it is significant that this paper is as contemporary now as it was then, over 20 years ago. We think this says much about the stagnation in the field of research on girls and physical education. As we have tried to show in this paper, some responsibility for the maintenance and reproduction of the same old narrative about girls and physical education must be borne by researchers and by the media reporting the findings of their research. We think there are a number of possible explanations for this situation, which suggest in turn potential solutions.

First, we think that this topic of study, like the broader field of physical education and sport pedagogy (Kirk, 2010), is marred by poor citation practices and a consequent general lack of systematic building on previously published studies. Perhaps research on girls and physical education has been too small scale, or has failed to be rigorous enough methodologically, so that this research isn't worth citing? But then, even if this was the case, why do successive studies, even those with standard public health designs featuring large numbers of participants, quantification and randomised trials, repeat the findings of previous research that has none of these features? Or perhaps the problem is that researchers from a range of fields, such as physical education and sport pedagogy on the one hand and public health on the other, are unaware of each other's work since they publish in different journals and attend different conferences? While this may be an explanation for poor citation practices, it is not in our view an excuse, since any careful and thorough literature search should bring appropriate published research to light.

Second, poor citation practices may lie at the base of the apparently random, scattergun nature of research on girls and physical education. There appear to be few programmes of research and a marked absence of a broader programme of interlocking research studies that could produce genuine developments in practice or, at least, the evidence that could illustrate what is possible in terms of improving the situation for girls and physical education. To facilitate a programmatic approach, we think researchers in the field need to be willing to 
identify and articulate a shared mission, with common, research-informed goals, vocabulary and methods (Kirk and Haerens, in press). Along with these shared and common values and approaches could come the capacity for researchers to develop a more assertive and collaborative relationship with media individuals and organisations so that the findings of research studies are reported accurately and that the 'news' is highlighted and foregrounded in their reports.

Finally, we do not underestimate the scale of the challenge facing researchers to contribute to improving the situation for girls in physical education. We suggest that, as pedagogues, we must take a pragmatic approach, asking whether we can make a difference for the better, what 'better' would be, and how do we go about this task? Instead of perpetuating the same old story, we need to start with what we know about what does in fact facilitate girls' interest, motivation and learning in physical education. Activist scholars could provide us with a lead to assist in answering the three pragmatist question (eg. Enright \& O'Sullivan, 2010; 2012; Fiestte, 2011; Fisette \& Walton 2011; Oliver, Hamzeh \& McCaughtry 2009; Oliver \& Lalik, 2004; Oliver \& Oesterreich, 2013;). Through their change-focused research projects, they have identified some of the critical elements that $d o$ facilitate girls' engagement with physical education, including being student-centred, creating opportunities for girls to study issues of embodiment, inquiry-based education centred in action, and listening and responding to girls over time. These critical elements allow us to develop programmes that meet the needs of different girls in different contexts, and show that there is no one best highly prescribed way to work with girls. Learning from activist researchers, we conclude with the proposal that a large part of a shared mission for this field of inquiry is that it must become more focused on how we go about improving the situation for girls in physical education, building on what we already know from activist studies and other student-centred inventions. 


\section{References}

Azzarito, L.M., and M.A. Solmon. 2006. “A Poststructural Analysis of High School

Students' Gendered and Racialized Bodily Meanings.” Journal of Teaching in Physical Education 25 (1): 75-98.

Barr-Anderson, D. J., D. Neumark-Sztainer, L. Lytle, K. H. Schmitz, D. S. Ward, T. L. Conway, C. Pratt, C. D. Baggett, and R. R. Pate. 2008. "But I Like PE: Factors Associated With Enjoyment of Physical Education Class in Middle School Girls.” Research Quarterly for Exercise and Sport 79 (1): 18-27.

Benn, T., Dagkas, S., and Jawad, H. 2011. "Embodied faith: Islam, religious freedom and educational practices in physical education." Sport, Education and Society, 16(1), 17-34.

Birchley, E. 2012. "PE 'Puts Half Of Girls Off Exercise For Life."' Sky News. http://news.sky.com/story/14720/pe-puts-half-of-girls-off-exercise-for-life

Campbell, D. 2005. "Ugly Games Kit Turns Girls Off PE." The Guardian. http://www.guardian.co.uk/uk/2005/jan/16/health.schools

Casey, M., Mooney, A., Eime, R., Harvey, J., Smyth, J., Telford, A. and Payne, W. 2013. "Linking Physical Education With Community Sport and Recreation: A Program for Adolescent Girls." Health Promotion Practice, 14 (5), 721 -731.

Constantinou, P., Manson, M. and Silverman, S. 2009. "Female Students' Perceptions About Gender Role Stereotypes and Their Influence on Attitude Toward Physical Education.” The Physical Educator, 66(2), 85-96.

Enright, E., and M. O’Sullivan. 2010. “'Can I Do It in My Pyjamas?' Negotiating a Physical Education Curriculum with Teenage Girls.” European Physical Education Review 16 (3): 203-222.

Enright, E., and M. O’Sullivan. 2012. “Physical Education 'In All Sorts of Corners': Student Activists Transgressing Formal Physical Education Curricular Boundaries.” Research Quarterly for Exercise and Sport 83 (2): 255-267. 
Faulkner, K. 2012. "Grubby Changing Rooms and Embarrassment at Getting Sweaty in Front of Boys Mean PE Lessons are Putting Girls Off Exercise for Life.” Mail Online.

http://www.dailymail.co.uk/health/article-2138182/Grubby-changing-rooms-embarrassmentgetting-sweaty-boys-mean-PE-lessons-putting-girls-exercise-life.html

Felton, G., Saunders, R.P., Ward, D.S., Dishman, R.K., Dowda, M., Pate, R.R. 2005.

"Promoting Physical Activity in Girls: A Case Study of One School's Success." Journal of School Health, 75(2), 57-62.

Fisette, J. L. 2011. 'Negotiating Power within High School Girls' Exploratory Projects in Physical Education.” Women in Sport and Physical Activity Journal 20 (1): 73-90.

Fisette, J. L., and T. A. Walton. 2011. “'If You Really Knew Me'...I Am Empowered Through Action." Sport, Education and Society 1-22. doi:10.1080/13573322.2011.643297.

Flintoff, A., and Sheila S. 2006. "Girls and Physical Education.” In The handbook of physical education, edited by David Kirk, Doune Macdonald, and Mary O’Sullivan, 767-783. London: Sage.

Garner, R. 2012. “'Unfeminine' School Sports Leave Girls on the Sidelines.” The Independent. http://www.independent.co.uk/news/education/education-news/unfeminineschool-sports-leave-girls-on-the-sidelines-7704402.html

Gibbons, S.L. 2009. "Meaningful Participation of Girls in Senior Physical Education Courses." Canadian Journal of Education, 32 (2), 222-244.

Grieser, M., Vu, M.B., Bedimo-Rung, A.L., Neumark-Sztainer, D., Moody, J., Rohm Young, D. and Moe, S.G. 2006. "Physical Activity Attitudes, Preferences, and Practices in African American, Hispanic, and Caucasian Girls" Health Education \& Behavior, 33(1), 40-51.

Hills, A. 2006. "Playing the Field(s): An Exploration of Change, Conformity and Conflict in Girls’ Understandings of Gendered Physicality in Physical Education.” Gender and Education 18 (5): 539-556. 
Hughes, J. 2012. "Girls and Sport: Schools Urged to Make PE More Attractive to Girls". BBC News. http://www.bbc.co.uk/news/health-17873519

Kirk, D. and Haerens, L. in press. "New Research Programmes in Physical Education and Sport Pedagogy." Sport, Education and Society

Kirk, D., 2010. "Porquê de investigar: estado atual e tendências futuras nas pesquisas em Educação Física." (Why research matters: Current status and future trends in physical education pedagogy.) Movimeto, 16(2), 11-43.

McKenzie, T. L., J. F. Sallis, J. J. Prochaska, T. L. Conway, S. J. Marshall, and P. Rosenguard. 2004. "Evaluation of a Two-Year Middle-School Physical Education Intervention: M-SPAN.” Medicine \& Science in Sports \& Exercise, 36(8), 1382-1388.

Oliver, K. L., M. Hamzeh, and N. McCaughtry. 2009. “'Girly Girls Can Play Games/Las Niñas Pueden Jugar Tambien': Co-creating a Curriculum of Possibilities With $5^{\text {th }}$ Grade Girls.” Journal of Teaching in Physical Education 28 (1): 90-110.

Oliver, K. L., and R. Lalik. 2004. “'The Beauty Walk, This Ain't My Topic': Learning About Critical Inquiry with Adolescent Girls.” Journal of Curriculum Studies, 36(5), 555-586.

Oliver, K. L., and R. Lalik. 2004. "Critical Inquiry on the Body in Girls' Physical Education Classes: A Critical Poststructural Analysis.” Journal of Teaching in Physical Education 23 (2): 162-195.

Oliver, K. L., and H. A. Oesterreich. 2013. "Student-centred Inquiry as Curriculum as a Model for Field-based Teacher Education.” Journal of Curriculum Studies 43 (3): 394-417.

Shen, B., Rinehart-Lee, T., McCaughtry, N. and Li, X. 2012. "Urban African-American Girls' Participation and Future Intentions Toward Physical Education.” Sex Roles, 67:323333.

Taylor, W. C., A. K. Yancey, J. Leslie, N. G. Murray, S. S. Cummings, S. A. Sharkey, C. Wert, J. James, O. Miles, and W. J. McCarthy. 2000. "Physical Activity Among African 
American and Latino Middle School Girls: Consistent Beliefs, Expectations, and Experiences Across Two Sites.” Women \& Health 30 (2) 67-82. doi: 10.1300/J013v30n02_05

Vertinsky, P. A. 1992. "Reclaiming Space, Revisioning the Body: The Quest for Gendersensitive Physical Education." Quest 44 (3): 373-396.

Walker, Harriet. 2012. "I Blame the Psychotic Gym Teachers.” The Independent. http://www.independent.co.uk/voices/commentators/harriet-walker-i-blame-the-psychoticgym-teachers-7704401.html

Ward, J., Wilkinson, C., Vincent Graser, S. and Prusak, K.A. 2008. "Effects of Choice on Student Motivation and Physical Activity Behavior in Physical Education." Journal of Teaching in Physical Education, 27, 385-398.

Women's Sport and Fitness Foundation. 2012. "Changing the Game for Girls." http://www.wsff.org.uk/system/1/assets/files/000/000/285/285/f4894dccf/original/Changing_ The_Game_For_Girls_Final.pdf

Women's Sport and Fitness Foundation. 2010. 'Young Women and Girls' Physical Activity: Fact Sheet." Author. 